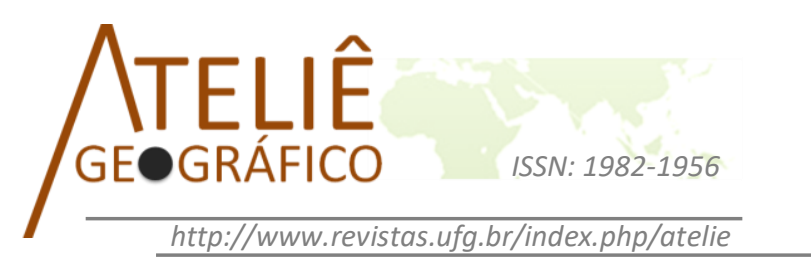

\title{
O desenvolvimento socioeconômico do Pontal do Triângulo Mineiro: uma análise das atividades do campo e da cidade em Frutal (MG) e em Ituiutaba (MG)
}

\author{
The socioeconomic development of Triângulo Mineiro Pontal: an \\ analysis of the activities from the countryside and the citie in Frutal \\ (MG) and Ituiutaba (MG)
}

\section{El desarrollo socioeconómico de Pontal Triangulo Minero: un análisis de las actividades del campo y la ciudad en Frutal (MG) y Ituiutaba \\ (MG)}

\author{
Letícia Parreira Oliveira \\ Universidade Federal de Uberlândia \\ leticia.p.geo@gmail.com \\ Vitor Ribeiro Filho \\ Universidade Federal de Uberlândia \\ ribeirofilho.vitor@gmail.com
}

\begin{abstract}
Resumo
O presente trabalho tem como objetivo compreender as formações socioeconômicas de Frutal (MG) e Ituiutaba (MG) que levam a entender as relações estabelecidas na atualidade por meio da análise da centralidade urbana no contexto do Pontal do Triângulo Mineiro. Os passos metodológicos permitiram atingir o objetivo estabelecido, haja vista que eles perpassaram pelo levantamento teórico composto por dados secundários e dados primários em campo e nas secretarias municipais. Desse modo, foi possível entender as distinções e similaridades entre os dois municípios, identificando a dinâmica da região do Triângulo Mineiro (MG). Na atualidade, as rodovias, a polarização e os fluxos identificam as relações estabelecidas com suas hinterlândias, sendo que essas estão ligadas às categorias de análises, sobretudo, às do setor da saúde e do ensino superior devido as suas complexidades em relação às cidades do entorno. Desse modo, as microrregiões de Frutal (MG) e Ituiutaba (MG) apresentam algumas ligações, que se tornam mais restritas ao se avaliar os municípios sedes. Há a presença de duas ilhas: Frutal (MG), que estabelece relações com o estado de São Paulo e com as cidades de Uberlândia (MG) e Uberaba (MG), e Ituiutaba (MG), que se relaciona com as cidades de sua microrregião.
\end{abstract}

Palavras-chave: Centralidade urbana. Frutal (MG). Ituiutaba (MG). 


\begin{abstract}
This study aims to understand the socioeconomic formations from Frutal (MG) and Ituiutaba (MG) that lead to understand the relationships established nowadays through the analysis of urban centrality in the context of Pontal do Triângulo Mineiro. The methodological steps enable to achieve the stated goal, considering that they pass by theoretical research, secondary data and primary data in the field and in the Municipal Office. Thereby, it was possible to understand the distinctions and similarities between the two cities, identifying the dynamics of Triângulo Mineiro (MG). Currently, highways, the polarization and flows identify the relationships between their hinterlands, and these are connected to the analysis categories, especially those from the health sector and higher education due to their complexities in relation to the surrounding cities. Thus, the microregions of Frutal (MG) and Ituiutaba (MG) have small links, the ones that become more restricted when evaluating the headquarters municipalities. There are two islands: Frutal (MG) establishing relations with the state of São Paulo and with the cities Uberlândia (MG) and Uberaba (MG), and Ituiutaba (MG), that relates to the cities of its micro region.

Keywords: Urban centrality, Frutal (MG), Ituiutaba (MG).
\end{abstract}

\title{
Resumen
}

Este estudio tiene como objetivo comprender las formaciones socioeconómicas de Frutal (MG) y Ituiutaba (MG) que llevan a comprender las relaciones que se establecen hoy en día através del análisis de centralidad urbana en el contexto de Pontal do Triângulo Mineiro. Los pasos metodológicos posibilitaron alcanzar el objetivo fijado, dado que envolvieron investigación teórica hecha con datos secundarios y datos primarios recogidos en campo y en las oficinas municipales. Por lo tanto, fue posible entender las diferencias y similitudes entre los dos municipios que identifican la dinámica de la región Triangulo Mineiro (MG). Actualmente, las carreteras, la polarización y los flujos identifican las relaciones que se establecen con sus zonas de influencia, y estos están conectados con las categorías de análisis, sobre todo, al sector de la salud y la educación superior debido a sus complejidades en relación a las ciudades de los alrededores. Así, las microrregiones Frutal (MG) y Ituiutaba (MG) tienen algunas conexiones, las que se vuelven más estrictas al evaluar los municipios sede. Nos quedamos con la presencia de dos islas: Frutal (MG), con relaciones con el Estado de São Paulo y las ciudades de Uberlandia (MG) y Uberaba (MG), y Ituiutaba (MG), que se refiere a las ciudades de su microrregión.

Palabras clave: Centralización urbano. Frutal (MG). Ituiutaba (MG).

\section{Introdução}

A abrangência cada vez maior do desenvolvimento técnico-científico que atingiu a agroindústria implicou na maior interação do meio rural com o urbano, modificando as formações e as relações territoriais. Desta forma, discutir a realidade da mesorregião do Triângulo Mineiro, com foco no Pontal, é essencial, pois ela se insere nesses preceitos como importante região no estado de Minas Gerais, o que se justifica por meio dos dados populacionais, visto que ela apresenta $10,94 \%$ da população mineira (IBGE, Instituto Brasileiro de Geografia e Estatística, 2010).

Por conseguinte, entender as dinâmicas socioeconômicas de duas cidades de suas microrregiões se torna fundamental para analisar e avaliar a estrutura dessa mesorregião, visto que essas cidades apresentam distinções quanto à estrutura e formação. Assim, as Microrregiões Geográficas de Frutal (MG) e Ituiutaba (MG) vêm se alterando, sobretudo nos processos de urbanização. 
A microrregião de Ituiutaba (MG) apresenta uma população total de 143.348 habitantes (IBGE, 2010), distribuída por seis municípios: Cachoeira Dourada (MG), Capinópolis (MG), Gurinhatã (MG), Ipiaçu (MG), Ituiutaba (MG) e Santa Vitória (MG). Desses, apenas o município de Ituiutaba (MG) tem uma população acima de 50 mil habitantes, chegando a 2010 com um total de 97.171 (IBGE, 2010). Os demais municípios não ultrapassam a totalidade de 20 mil habitantes, cada um.

A microrregião de Frutal (MG) - inserida na região do Pontal do Triângulo Mineiro, juntamente com a de Ituiutaba (MG) - possui um total de 179.512 habitantes (IBGE, 2010), sendo a de Frutal (MG) a que possui o maior número de municípios da mesorregião do Triângulo Mineiro/Alto Paranaíba, totalizando doze: Campina Verde (MG), Carneirinho (MG), Comendador Gomes (MG), Fronteira (MG), Frutal (MG), Itapagipe (MG), Iturama (MG), Limeira do Oeste (MG), Pirajuba (MG), Planura (MG), São Francisco de Sales (MG) e União de Minas (MG).

Com base nessas observações, a proposta deste trabalho é válida para entender e enriquecer os estudos urbanos no Triângulo Mineiro (MG), sobretudo da região do Pontal.

Desta forma, a escolha dos dois municípios pesquisados - Frutal (MG) e Ituiutaba (MG) - se justifica por eles serem sedes das duas microrregiões que compõem o Pontal, bem como por apresentarem desenvolvimento e dinâmicas que proporcionam e instigam análises contemporâneas direcionadas a sua centralidade urbana.

A metodologia proposta para a pesquisa perpassou por etapas que foram realizadas individualmente ou de forma simultânea para uma melhor estruturação do trabalho. O primeiro passo consistiu no levantamento bibliográfico sobre o tema estudado, evidenciando a necessidade de se conhecer melhor o que já se tem pesquisado e publicado sobre o assunto, a fim de ter mais informações sobre o tema e ampliar os estudos sobre o Pontal do Triângulo Mineiro. Todo esse processo inicial foi essencial para a base da pesquisa. Portanto, é fundamental também abranger as referências que auxiliam a entender a dinâmica da mesorregião do Triângulo Mineiro/Alto Paranaíba (MG) em relação ao processo de modernização da agricultura, visto que foi a partir desta atividade que a rede urbana da região se reestruturou, modificando a dinâmica das cidades nela inseridas. Com esse estágio realizado, a próxima etapa visou a compreender as análises sobre as dinâmicas socioeconômicas, as quais foram relacionadas a demais informações de fontes secundárias, como dados censitários e estatísticos, PIB, produção agropecuária, comércio e serviços, saúde, dentre outras. Esses últimos dados foram adquiridos nos sites do IBGE, CNES, UNICA, bem como nas prefeituras municipais e secretarias de educação e saúde. Dessa forma, foram selecionadas as categorias de análise e de levantamento com base nos estudos bibliográficos, nos levantamentos secundários e nos primeiros trabalhos em 
campo. São elas: agropecuária, agroindústria, comércio e serviços, franquias, saúde e instituições de ensino superior.

Para realizar essas análises socioeconômicas também foram levantados dados em campo em Frutal (MG) e Ituiutaba (MG), bem como em meio eletrônico. Nas cidades, foram observadas as áreas comerciais, sendo que os dados levantados se referiam à disposição do comércio, existência de franquias, lojas especializadas no segmento agropecuário, lojas de departamento, Secretaria da Fazenda e de Educação, bancos, concessionárias, armazéns, supermercados e instituições de ensino superior.

Primeiramente, foram trabalhadas as atividades desenvolvidas no campo, as quais regem parte da dinâmica da cidade, uma vez que é nela que são disponibilizados os bens e serviços que atendem a zona rural dos municípios. Em seguida, foram abordados o comércio e as franquias, no intuito de discutir sobre o consumo, assim como sobre a localização das franquias fora dos shopping centers, visando também atender um público maior e, por vezes, menos seletivo, o que gera atração para as cidades analisadas. Essa atividade exerce centralidade devido ao deslocamento das cidades da hinterlândia para Frutal (MG) e Ituiutaba (MG), visando o consumo das marcas específicas, conforme identificado nos trabalhos de campo. Já a opção pelo setor da saúde, também sobre o contexto de atratividade, embasa-se nos acordos regionais e nos níveis de complexidade desenvolvidos nos hospitais, bem como no maior número de especialidades encontradas nas cidades estudadas por meio de clínicas e laboratórios.

Para isso, a centralidade urbana se revela por meio da instalação de algumas atividades, como as relacionadas ao ensino superior, uma vez que elas propiciam a atração de estudandes, professores e demais profisisonais. Sposito (1991) entende a centralidade urbana

[...] em primeiro lugar, da expressão a nível de espaço do que os estudiosos chamam a algum tempo de divisão social do espaço. Quer dizer, à medida que há distintas atividades e distintos níveis sociais ligados a estas atividades, esta divisão se espacializa e, ao espacializar-se, tem, a um só tempo, elementos de diferenciação, tanto a nível social como espacial (SPOSITO, 1991, p. 47).

É sob esse viés, de entender a centralidade urbana relacionada à formação socioespacial e ao processo de reunião das atividades, que se vinculam as discussões para Frutal (MG) e Ituiutaba (MG).

Para isso, vale entender como a relação cidade-campo acontece de forma distinta nos lugares devido ao processo de globalização e urbanização, assim como de reorganização produtiva (HESPANHOL, 2013), o que leva a análise de cada local a uma conjuntura particular de observação, de pesquisa e de discussão.

Portanto, nos dois municípios estudados, o campo se dinamiza e se moderniza no decorrer dos anos; as cidades, igualmente, sofrem interferências, especialmente no centro comercial e na área central. Por conseguinte, nesse âmbito, quanto "mais 
modernizada a atividade agrícola, mais amplas são as suas relações, mais longíquo o seu alcance“" (SANTOS, 1988, p. 54).

Com base na análise realizada anteriormente, serão abordados nos itens seguintes as temáticas de agropecuária, indústria, comércio e serviços, franquias, saúde e ensino superior em Frutal (MG) e Ituiutaba (MG).

\section{As relações socioespaciais em Frutal (MG): as atividades desenvolvidas no campo.}

O processo histórico de formação de Frutal (MG) indica que o município perpassou por momentos em que possuiu pontos relevantes para ampliar seu desenvolvimento, como sua disposição de ligação com o estado de São Paulo. Contudo, Frutal (MG) não conseguiu ampliar suas ligações e promover seu crescimento político e econômico nas primeiras décadas de sua emancipação, em 1885. Apesar disso, desde o início do século XXI, a cidade vem engendrando novos passos.

Em 2014, com uma população total estimada em 57.720 habitantes (IBGE, 2014), Frutal (MG) viu sua dinâmica urbana ser modificada, com base na movimentação da economia direcionada às atividades agroindustriais e agropecuárias.

Segundo Reis de Paula (2012), o município apresenta uma criação de gado em confinamento que movimenta vários setores da economia local, perpetuando-se na disponibilidade de bens e serviços, bem como no aumento de empregos e na base salarial municipal. $\mathrm{O}$ autor ainda trabalha mostrando que esses fatores - voltados às atividades do campo - estão ligados à estruturação da cidade, especialmente, do centro comercial e avenidas em que se instalam as atividades que ofertam serviços e produtos ao campo.

Segundo dados do IBGE, em 2010 foram produzidos 47.319 mil litros de leite no município, valor inferior aos anos anteriores, sendo que em 2000 a produção chegou a 50.998 mil litros. Entre os anos de 2000 e 2010, a produção reduziu em 3.679 mil litros de leite. Tanto essa queda na produção quanto no número de cabeças de gado pode ser justificada pela inserção de novas monoculturas no campo, como a cana-deaçúcar - apontada pelos dados do IBGE que serão discorridos adiante -, que utilizam amplas áreas até então destinadas à pastagem e à criação de bovinos.

Nas atividades agrícolas, Minas Gerais é o terceiro maior produtor de laranja no Brasil. O Triângulo Mineiro/Alto Paranaíba (MG) é a mesorregião com a maior produção no estado, com 650.357 toneladas (IBGE, 2010c). A microrregião de Frutal (MG) é a que apresenta os maiores números de produção de laranja na mesorregião geográfica, chegando a 2012 com 470.000 toneladas colhidas, sendo Uberlândia (MG) a segunda maior produtora, com 98.625 toneladas (IBGE, 2012).

Até 2012, o municipio de Frutal (MG) apresentava o maior índice de colheita dessa monocultura, com 243.000 toneladas, seguido de Comendador Gomes (MG), com 200.200 toneladas (IBGE, 2012). Os dois municípios são responsáveis por 
aproximadamente 68,14\% da produção de laranja no Triângulo Mineiro/Alto Paranaíba (MG).

Apesar da diminuição na colheita de laranja entre 2000 e 2010, ela ainda se apresenta como uma importante atividade econômica em Frutal (MG), visto que as empresas que processam e recebem essa matéria-prima se localizam principalmente ao sul do município e no estado de São Paulo, por exemplo, em Colina (SP), Araraquara (SP), Bebedouro (SP) e Catanduva (SP).

A cana-de-açúcar ocupa a maior porcentagem da produção agrícola no campo de Frutal (MG). Em 2010, segundo o IBGE, foram colhidas 2.455 .120 toneladas de cana, sendo que, em 2012, ela atingiu 3.825.000 toneladas, com uma área total de colheita de 69.292 hectares na safra 2012/2013 (ÚNICA, 2014).

Quando analisada toda a microrregião, Frutal (MG) apresenta 12,65\% de sua área destinada ao plantio de cana-de-açúcar, ao passo que Pirajuba (MG), Fronteira (MG), Planura (MG) e Iturama (MG) apresentam as maiores porcentagens de hectares de cana com $42,42 \%, 26,45 \%, 23,62 \%$ e $22 \%$, respectivamente.

Contudo, Frutal (MG) e Iturama (MG) são os municípios com maior número de hectares com plantio dessa monocultura, respectivamente 30.689 e 30.900 hectares. Com relação à Frutal (MG), a análise da produção agrícola entre os anos de 1920 e 2010 reforça as discussões realizadas ao destacar o plantio dos grãos - arroz e milho até 1973 e a ascensão da produção de soja em 1980, mesmo ano em que a produção de cana começou seu processo de crescimento, mantido até a atualidade (figura 1).

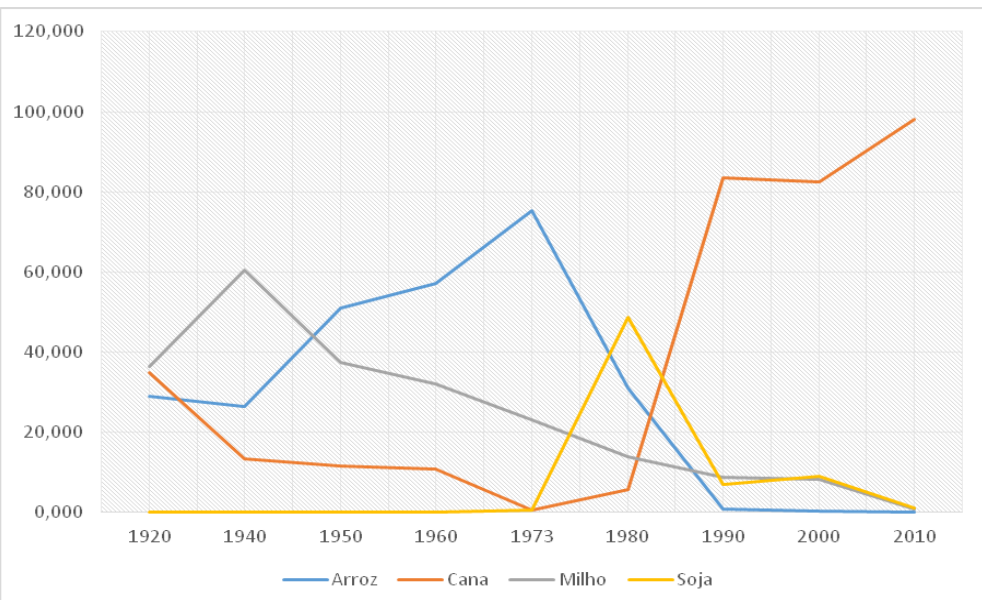

Figura 1 - Frutal (MG): produção por tipo de cultura - tonelada (1920-2010). Fonte: IPEADATA (2014).

Organização: Letícia Parreira Oliveira, 2014. 
O plantio de cana-de-açúcar cresceu não somente em Frutal (MG), mas também em todo Triângulo Mineiro/Alto Paranaíba (MG), seguindo o percursso realizado também pelo país. Segundo dados do IBGE, o Brasil, em 2000, possuía 4.879.841 hectares e, em 2010, chegou a 9.164.756 hectares de cana plantados.

A expansão da cana-de-açúcar, nos períodos de 2005 a 2010 na região do Triângulo Mineiro/Alto Paranaíba (MG), identifica as maiores áreas do plantio dessa monocultra nos municípios, marcadamente, das microrregiões de Frutal (MG), Ituiutaba (MG) e Uberaba (MG). Conforme os dados do IBGE, a mesorregião passou de 126.500 hectares destinados à monocultura da cana, em 2000, para 492.440 hectares, em 2010. A fertilidade do solo, próximo aos vales dos rios Paranaíba e Grande, também é essencial para a ampliação do plantio da cana-de-açúcar, sobretudo em Ituiutaba (MG), Iturama (MG) e Frutal (MG); já as áreas de solos com fertilidade reduzida apresentam ausência dessa monocultura e manejo da pecuária, principalmente na porção central do Pontal do Triângulo Mineiro.

Para entender e analisar a expansão da indústria canavieira, bem como do cultivo da cana-de-açúcar no Triângulo Mineiro (MG), é importante "considerar que esta resulta da ampliação da política de incentivo à produção de agrocombustíveis, que atrai investimentos de grupos paulistas, nordestinos, além de investidores estrangeiros" (SANTOS, 2011, p. 270).

Esse aumento dos incentivos à produção canavieira no Brasil e, portanto, aceleração do crescimento em larga escala das áreas de plantio da cana-de-açúcar, bem como a abertura de novas usinas de beneficiamento e ocupação de novos espaços, consistem "na valorização da bioenergia, por meio do etanol e do biodiesel" (SANTOS, 2011, p. 268).

Com destaque à produção sucroenergética, vale ressaltar o papel do PROÁLCOOL na década de 1990, época que foi marcada

[...] pela concentração industrial e retração da produção de álcool hidratado sob a desregulamentação parcial, haja vista que o Governo Collor inaugurou a diminuição da intervenção estatal nas atividades produtivas. Foi nesse contexto que os empresários do setor sucroalcooleiro reivindicaram a manutenção do PROÁLCOOL, mediante solicitação de novos recursos públicos, redução de impostos e renegociação das dívidas junto ao Estado, em um cenário marcado pelo neoliberalismo, competitividade e uma onda de privatizações em vários setores da economia (SANTOS, 2009, p. 127).

Portanto, as usinas sucroenergéticas assumem um papel na dinamização do campo nos municípios onde se instalam, tornando as cidades um espaço complementar ao outro, uma vez que ocorre o aumento no número de empregos, bem como de renda e de consumo. Com maior poder de aquisição, a população busca a obtenção de bens materiais, o que dinamiza também o comércio local.

A quantidade de área plantada em hectares de cana-de-açúcar no estado mineiro mais que duplicou em dez anos, passando de 292.571 hectares, em 2000, para 
746.527 hectares, em 2010 (IBGE, 2010c). Já a plantação dessa monocultura na mesorregião do Triângulo Mineiro/Alto Paranaíba (MG) e na microrregião de Frutal (MG) mais que triplicou, crescendo acima da média de Minas Gerais.

Ainda sobre essa atividade, vale destacar que Frutal (MG) conta com a presença de duas usinas que se utilizam da cana-de-açúcar plantada em seu munícipio: Usina de Álcool e Açúcar Frutal e Usina Cerradão. A Usina de Frutal pertence ao Grupo Bunge e iniciou sua produção em 2007. Já a Usina Cerradão, instalou-se em Frutal (MG) no ano de 2009 por meio de intervenções e projetos realizados pelos Grupos Queiroz de Queiroz e Pitangueiras.

De forma relacionada, nota-se a presença de capital paulista nas atividades agropecuárias em Frutal (MG), tendo em vista que alguns grupos agropecuários têm suas bases na região de Ribeirão Preto (SP), como o Grupo JP Andrade Agropecuária.

A injeção de capital desse tipo, aliada a outros fatores, como a ampliação nas últimas décadas da produção canavieira no estado de São Paulo e a localização privilegiada de Frutal (MG) nesse contexto territorial, levaram a uma expansão nos últimos anos do número de usinas de álcool, açúcar e energia instaladas em Frutal (MG) e outros municípios da sua microrregião, assim como aumento do número de hectares destinados ao plantio dessa monocultura, como já foi constatado nos dados apresentados anteriormente. Seguindo essa linha, tem-se a criação da APROVALE (Associação de Produtores de Cana do Vale do Rio Grande).

A mecanização nesse setor também chegou aos campos de Frutal (MG) e de sua microrregião, carregando pontos positivos e negativos. De um lado, esse processo diminui o número de mão-de-obra ocupada, colocando as máquinas para exercer as atividades realizadas antes por trabalhadores, do outro, tem-se a diminuição da fuligem oriunda da queima da cana realizada antes do seu corte, bem como a diminuição de pessoas advindas da migração, visto que a cidade nem sempre apresenta aportes habitacionais, de saúde e saneamento básico para atender a demanda que chega de forma repentina.

As usinas são importantes mantenedoras de mão-de-obra em Frutal (MG). Essa força de trabalho vem do próprio município e de outros, em razão da sua proximidade com as cidades paulistas.

Portanto, toda essa dinâmica favorece a criação de empregos no campo e na cidade. Segundo IBGE (2010), Frutal (MG), com 25.790 das pessoas com 10 anos ou mais ocupadas, possui o maior número de pessoas exercendo atividades ligadas à agricultura, pecuária, produção florestal, pesca e aquicultura, totalizando 4.885 pessoas nessas atividades. Outras 5.690 estão trabalhando na área comercial ou de reparos em veículos automotores ou motonetas. Em seguida, tem-se o total de 3.459 pessoas concentradas no trabalho nas indústrias de transformação. Vale destacar que, em 2006, o total de estabelecimentos agropecuários em Frutal (MG) era de 1.556, com um total de 4.165 pessoas ocupadas. 
Esses dados demonstram que o município apresenta suas bases econômicas no campo e nas atividades comerciais, que, por sua vez, geram mais empregos para a população local. As informações condizem com o Produto Interno Bruto (PIB) de cada atividade econômica. Segundo o IBGE (2011), a agropecuária apresentava um valor de $\mathrm{R} \$ 361.310$, segundo maior valor no município, visto que o destaque vai para a prestação de serviços, que chega a $\mathrm{R} \$ 511.818$.

Desse modo, as análises do campo estão relacionadas com as exercidas na cidade e, sendo assim, com o intuito de complementar a discussão dos dados apresentados para se atingir o objetivo final de aprofundamento sobre a centralidade urbana, o próximo tópico discorre sobre os dados referentes ao contexto urbano de Frutal (MG), levando em conta os setores de saúde, de ensino supeior, comercial e de franquias.

\section{Centralidade urbana: Frutal (MG) e seu centro comercial}

As atividades executadas no campo se refletem na cidade por meio da inserção de novos comércios e serviços, assim como pela diversificação das oportunidades de formação profissional, todos visando atender às demandas geradas na zona rural dos municípios. Em Frutal (MG), isso ocorre e vem se reforçando na última década, acima de tudo, devido aos cursos em nível superior que abordam tanto as atividades exercidas no campo como as do setor comercial, que atende a população.

Segundo dados do IBGE, de 2006 para 2012, o número de empresas em unidades locais em Frutal (MG) passou de 1.616 para 1.969, sendo que o valor gasto com salários e outras remunerações mais que triplicou nesse mesmo período, chegando a R \$ 197.887 em 2012. O total de pessoas assalariadas ocupadas passou de 6.613, em 2006, para 10.724, em 2012.

As franquias são um ramo empresarial que cresce no Brasil abarcando o âmbito comercial, principalmente o alimentício e o de serviços. O setor franchinsing no país gerou 1.029.681 empregos com um total de 114.409 unidades franqueadas, faturando $\mathrm{R} \$ 115,582$ bilhões (ABF, 2013).

Frutal (MG) apresenta 15 franquias $^{1}$ distribuídas nos seus diversos segmentos, desde o setor alimentício até o ensino de idiomas, como mostra o quadro 1. Dentre essas, a Água Doce Cachaçaria, instalada na cidade em 2010, apresenta aproximadamente 100 lojas distribuídas pelo Brasil, com enfoque nas cidades paulistas. Em Minas Gerais, além de estar em Frutal (MG), ela pode ser encontrada em Poços de Caldas (MG), Pouso Alegre (MG), Uberlândia (MG) e Varginha (MG). Portanto, notase que todas as cidades mineiras com essa franquia, exceto Frutal (MG), apresentam população superior a 130 mil habitantes. Além disso, para possuir essa franquia, o empresário precisa desembolçar aproximadamente $\mathrm{R} \$ 350$ mil para estruturar o bar.

\footnotetext{
${ }^{1}$ A escolha por destacar algumas franquias e discorrer sobre elas vem das análises realizadas em campo que identificaram as que apresentam maior destaque e importância para as cidades estudadas.
} 
Quadro 1 - Frutal (MG): franquias (2014).

\begin{tabular}{|l|c|}
\hline Alimentação & Cacau Show | Chiquinho Sorvetes \\
\hline Cosmético e perfumaria & O Boticário | Provanza Aromas e Sabores | Água de Cheiro \\
\hline Comidas e Bebidas & Água Doce Cachaçaria \\
\hline Farmácia & CCAA \\
\hline Ensino de idiomas & Microlins \\
\hline Escola de Informática & Sistema Objetivo | Kumon \\
\hline Escolar & Localiza \\
\hline Locação de veículos & Crogasil | Ultra Popular \\
\hline
\end{tabular}

Fonte: Trabalho de Campo

Organização: Letícia Parreira Oliveira, 2014.

No centro comercial de Frutal (MG) se concentram, além das franquias, todo comércio e serviço de vestuário, alimentação, escritórios (advocacia, imobiliária, contabilidade), farmácias, óticas, clínicas (odontologia, oftamologia), loja agropecuária, lojas de departamento (Eletrosom, Eletrozema, Casas Bahia, Móveis Estrela e Lojas Pernambucanas), oficinas, lojas de móveis, cartórios, correios, agências de viagens, bem como a rede bancária e administração pública da cidade.

No centro comercial também se encontram as instituições financeiras. Frutal (MG) possui no total 8 bancos, dentre eles, o Branco do Brasil e o Bradesco. Contudo, o destaque vai para os bancos SICOOB (Sistema de Cooperativa de Crédito do Brasil) e a CREDICITRUS (Cooperativa de Crédito Rural Coopercitrus), que tendem a atender os empresários e produtores que trabalham com o campo, com a agropecuária ou com a agroindústria.

Outro setor de importante inserção comercial é o do ramo da saúde. Nesse sentido, destaca-se em Frutal (MG) a presença de dois hospitais: o São José, que data de 1970, e o hospital Frei Gabriel, construído nas bases do antigo hospital São Franscisco de Assis, especializado em atendimentos de emergência (REIS DE PAULA, 2013).

Os atendimentos em Frutal (MG) são da ordem de baixa e média complexidade. Dos hospitais que realizam os atendimentos, um é de ordem privada e outro, pública. Além disso, Frutal (MG) conta com 4 postos de saúde, 11 centros de saúde (unidades básicas) ${ }^{2}, 8$ clínicas ou centros de especialidades ${ }^{3}, 80$ consultórios $^{4}$ e 8

\footnotetext{
2 "Unidade para realização de atendimento de atenção básica e integral a uma população, de forma programada ou não, nas especialidades básicas, podendo oferecer assistência odontológica e de outros profissionais de nível superior." (CNES, 2014)
} 
unidades de apoio à diagnose e terapia (SADT ISOLADO) (CNES, 2014), sendo 7 laboratórios e um banco de sangue.

Dos dados recentes, de janeiro a julho de 2014, o Hospital Frei Gabriel apresentava 2.168 internações - 237 eletivas e 1.931 em caráter de urgência - com 56 óbitos, apresentando assim uma taxa de mortalidade de 1,58 (CNES, 2014). O hospital atende desde consultas básicas até cirurgias do aparelho circulatório.

O Hospital São José se localiza na área comercial de Frutal (MG) e, por conseguinte, as atividades de saúde também estão em sua proximidade. Portanto, Frutal (MG) apresenta a área do setor de saúde que atende a população local e a das pequenas cidades de sua microrregião no que se refere à espeficicações de baixa e média complexidade.

Em relação ao ensino superior, Frutal (MG) possui uma Universidade Estadual de Minas Gerais, a UEMG, e a Faculdade Frutal, a FAF, sendo uma pública e a outra privada, totalizando 11 cursos disponíveis à população.

A FAF é uma instituição da Sociedade Frutalense de Ensino Superior Ltda vinculada à UNIESP - União das Instituições Educacionais do Estado de São Paulo. A Faculdade contava com 509 alunos $^{5}$ matriculados no segundo semestre de 2014.

A UEMG está em Frutal (MG) desde 2004 e foi estadualizada apenas em 2007. Os cursos foram implantados no decorrer dos anos conforme as demandas locais surgiam. O primeiro destes foi o de administração, já disponibilizado no ano inicial com 100 vagas.

Além dessas duas, Frutal (MG) ainda possui no campo do ensino superior:

[...] o Polo de Educação à Distância da Universidade Aberta do Brasil (UAB), com cursos de Química e Ciências Biológicas ofertados pela UFMG no campus UEMG; Universidade Paulista (UNIP), ITECON (Instituto de Educação Continuada). (REIS DE PAULA, 2012, p. 140).

Com dados adquiridos em campo, na UEMG, nota-se a presença de alunos oriundos de cidades paulistas, como Ribeirão Preto (SP), Colômbia (SP) e Barretos (SP). Também se observa a concentração de alunos de cidades com importantes universidades no Triângulo Mineiro (MG), como Uberlândia (MG) e Uberaba (MG). Contudo, a universidade ainda se direciona para os moradores locais e os que residem nas cidades de sua microrregião, tais como Itapagipe (MG), Planura (MG) e Fronteira (MG).

As pesquisas de campo realizadas indicaram que, devido à logística viária e sua proximidade com São Paulo, a maior parte dos alunos que frequentam a UEMG são ou do Triângulo Mineiro (MG) ou do noroeste paulista. Os estudantes dos municípios a

\footnotetext{
3 "Especializada e destinada à assistência ambulatorial em apenas uma especialidade/área de assistência". (CNES, 2014)

4 "Sala isolada destinada à prestação de assistência médica ou odontológica ou de profissionais de saúde de nível superior”. (CNES, 2014).

${ }^{5}$ Dados obtidos por meio de pesquisa de campo, adquiridos na secretaria da instituição.
} 
oeste da microrregião, sobretudo, Iturama (MG), Carneirinho (MG) e União de Minas (MG), tendem a se direcionar às instituições de ensino superior paulistas, como a de Fernandópolis (SP), a FEF - Fundação Educacional de Fernandópolis. Já Campina Verde (MG), devido justamente à posição da malha viária, direciona seu alunos à Ituiutaba (MG).

Portanto, todos os dados e informações apresentadas e discutidas para Frutal (MG) fundamentam as análises referentes à centralidade urbana, o que será tratado também para o município de Ituiutaba (MG), para, dessa forma, entender a análise entre os dois municípios sob a perspectiva da centralidade urbana.

\section{Atividades econômicas e o campo: atividades desenvolvidas e ligadas à agropecuária e à agroindústria em Ituiutaba (MG)}

Como já trabalhado a respeito de Frutal (MG), Ituiutaba (MG) também apresentou modificações nas suas atividades econômicas durante seu processo de formação histórico, com o ciclo do arroz, com a inserção agropecuária e, atualmente, com o enfoque na produção sucroenergética.

Já na segunda década do século XXI, Ituiutaba (MG) também se modificava em função da chegada das intituições federais a partir do ano 2000. Em 2014, com uma estimativa de 102.690 mil habitantes (IBGE, 2014), Ituiutaba (MG) viu outras mudanças acontecerem no setor educacional e na sua estrutura urbana, por exemplo, a estadualização da UEMG (Universidade Estadual de Minas Gerais), que era uma instituição de ensino superior privatizada.

Além desses fatores, as atividades do campo também impactam na dinamização e na estruturação urbana de Ituiutaba (MG). Lefebvre (2008, p. 109) afirma isso dizendo que "a cidade atrai para si tudo o que nasce, da natureza e do trabalho, noutros lugares: frutos e objetos, produtos e produtores, obras e criações, atividade e situações". Dessa forma, o setor agropecuário interfere diretamente na economia ituiutabana, visto que há a presença de indústrias voltadas às atividades do campo que beneficiam grãos, que industrializam a carne bovina, suína e de aves, assim como a produção de laticínios e, recentemente, as usinas sucroenergéticas, como se constata nas análises seguintes.

Ainda sobre as atividades do campo, a agricultura no setor de lavouras permanentes apresentava maior produção de laranja dentre as demais realizadas no município. Contudo, ela sofreu oscilações no decorrer dos anos, totalizando 12.648 toneladas em 2010, segundo dados do IBGE, sendo que a queda nesse período, em relação ao ano de 2000, é de 25.092 toneladas.

Durante anos, o plantio de arroz e milho dominava as plantações da microrregião de Ituiutaba (MG). Apesar disso, a chegada da cana-de-açúcar no Triângulo Mineiro (MG) e em Ituiutaba (MG) modificou esse contexto, como indica a 
figura apresentada mais adiante. A figura 2 reforça que a produção de arroz teve seu auge em 1950, sendo que, a partir desse ano, essa cultura passou a perder espaço para o milho, que se tornou a principal atividade agrícola municipal em 1980. A partir de 1990, a produção de milho diminuiu e abriu espaço para a chegada da cana-de-açúcar. Entre 2000 e 2010, a monocultura da cana aumentou sua produção, fazendo com que as demais culturas, de modo geral, diminuíssem seus espaços de plantio e colheita.

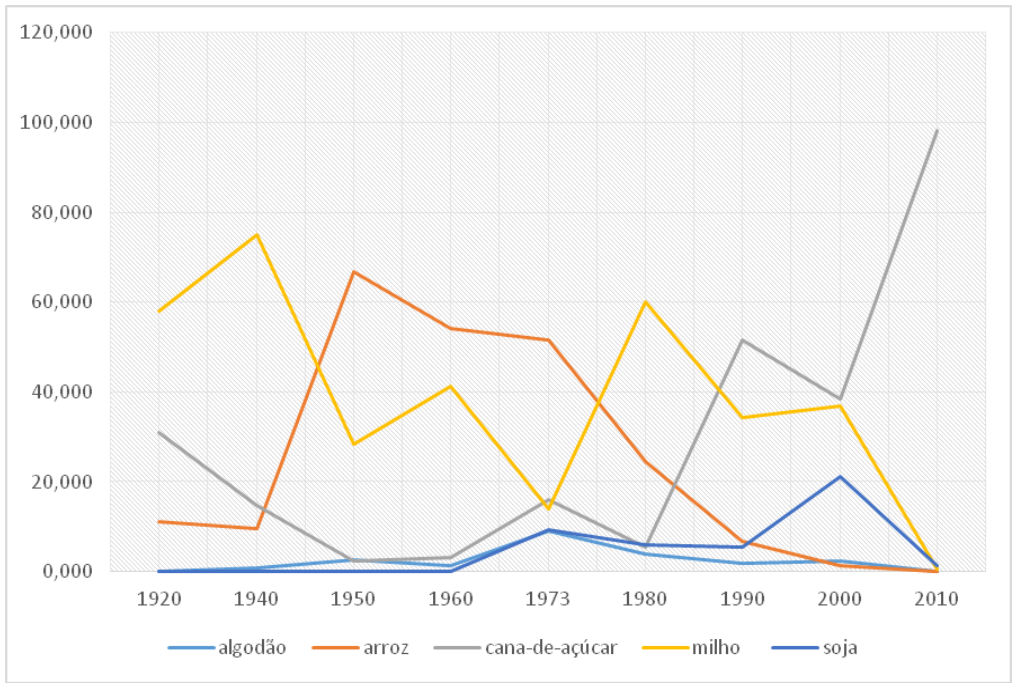

Figura 2 - Ituiutaba (MG): produção por tipo de cultura - tonelada (1920-2010) Fonte: IPEADATA (2014).

Organização: Letícia Parreira Oliveira, 2014.

O contexto urbano ituiutabano vivenciava essa realidade com a presença de comércios e serviços voltados às atividades econômicas desenvolvidas no campo, como a presença de comércio com disponibilização de produtos para o tratamento de animais, para o beneficiamento e armazenamento do leite, assim como lojas de medicamentos, vacinas e rações para o gado (OLIVEIRA, 2013).

Já no início do século, a cana-de-açúcar chegou a toda região com resquícios de sua expansão advinda do oeste paulista e fez com que as demais produções agrícolas decaíssem, sendo que as maiores quedas foram na de milho e de soja. Sobre essa expansão da cana, Santos (2011) afirma que:

[...] neste início de século XXI, o Cerrado é algo não apenas da ocupação dos sulistas, mas também de grupos multinacionais, que investem na aquisição de usinas e terras para o plantio de cana voltado à produção do etanol, provocando alterações nas relações sociais (SANTOS, 2011, p. 269). 
A cana-de-açúcar apresenta uma elevação de 35.000 toneladas, em 2000, para 1.680.000, em 2010, ano com maior índice de produção. Vale lembrar que da cana, além da fabricação do etanol, pode-se gerar energia com a queima do seu bagaço.

Em Ituiutaba (MG), o processo de inserção da cana interferiu no contexto municipal, desde a dinâmica urbana até a rural. Essa última foi modificada, visto que, com a instalação em 2008 da primeira usina de cana-de-açúcar em Ituiutaba (MG), ocorreu o aumento da:

[...] conversão de propriedades familiares em latifúndios monocultores. Inúmeras propriedades rurais passaram a ser compradas ou arrendadas para se cultivar a cana, anexando essas terras às áreas das usinas, resultando na expulsão de grande quantidade de pessoas que moravam nessas propriedades (FONSECA, SANTOS, 2011, p. 10).

A partir de 2010 ocorreu uma desaceleração no plantio dessa monocultura em Ituiutaba (MG), bem como uma pequena ascensão no de soja e de milho, em função dos investimentos e da chegada de novas usinas no município vizinho, Santa Vitória (MG).

Os dados referentes à microrregião mostram que Ituiutaba (MG) ocupa a terceira posição em porcentagem territorial de área plantada de cana-de-açúcar, porém fica em segundo em número total de hectares cultivados. A maior extensão de plantio é em Santa Vitória (MG), que chegou em 2010 a 25.867 hectares destinados à monocultura da cana.

Analisando as microrregiões do Triângulo Mineiro (MG), a de Ituiutaba (MG) é a que apresenta menor área plantada de cana-de-açúcar. A de Frutal (MG) fica com o maior número de hectares destinados a essa monocultura, sendo seguida pela microrregião de Uberaba (MG).

Segundo dados do IBGE, em 2010, Ituiutaba (MG) apresentava um total de 52.098 pessoas com 10 anos ou mais ocupadas, com destaque para: ocupações elementares $^{6}$, com um total de 11.984 pessoas, indústria de transformação, com 7.606, e trabalhadores qualificados - operários e artesãos da construção das artes mecânicas ou outros ofícios -, totalizando 7.036 pessoas. Já as áreas da agropecuária, produção florestal, pesca e aquicultura comportam 4.427 trabalhadores, sendo que 4.165 estão especificamente ocupados nos 1.443 estabelecimentos agropecuários. O próximo tópico aborda as demais atividades econômicas desenvolvidas na cidade de Ituiutaba (MG).

\section{Atividades econômicas e o contexto urbano de Ituiutaba (MG)}

Um fator que pode justificar os dados ocupacionais apresentados é o PIB (Produto Interno Bruto) de Ituiutaba (MG), com sua maior base nos serviços, que chegam a um valor de $\mathrm{R} \$ 1$ 175.277. Sequencialmente, tem-se a atividade industrial

\footnotetext{
${ }^{6}$ Policiais, bombeiros, militares e integrantes das forças armadas.
} 
com segundo maior aporte, $\mathrm{R} \$ 489.105$, e, por fim, a agropecuária, com $\mathrm{R} \$ 197.828$ (IBGE, 2011). Constata-se, portanto, que as atividades de serviços e comércio se destacam em Ituiutaba (MG) e a disponibilidade de empregos acompanha esse segmento, juntamente com os industriais.

O escoamento dessa produção agropecuária e industrial mostra a importância da malha viária ituiutabana. A malha viária do município tem uma relação direta com Uberlândia (MG) e o sudoeste goiano.

A disposição viária interfere também no setor da saúde, uma vez que Ituiutaba (MG) atende níveis de complexidade maiores que as pequenas cidades no seu entorno. A cidade conta com 78 estabelecimentos, dos quais 37 públicos, sendo que não há a presença de aparelho de ressonância magnética e mamógrafo com estéreotaxia ${ }^{7}$ (IBGE, 2009). A cidade conta com 3 hospitais: o São Joaquim, que apresenta atendimento exclusivo no âmbito particular; já o São José e o Nossa Senhora D’ Abadia, que apresentam atendimentos mistos, tanto privado, quanto pelo SUS.

Os atendimentos realizados têm características de baixa e média complexidade, com a disponibilização de apenas dois tipos de alta complexidade: a hemodiálise e a $\mathrm{UTI}^{8}$ (Unidade de Tratamento Intensivo).

Contudo, apesar de apresentar os elementos que definem o atendimento de alta complexidade, o que se constata é que Ituiutaba (MG) não possui esse aporte na saúde pública. Oliveira $(2013$, p. 373 ) prossegue afirmando que a "precariedade do sistema, a ausência de equipamentos técnicos e de profissionais, faz com que os casos médicos mais complexos sejam transferidos para a cidade de Uberlândia (MG)".

Com 2 postos de saúde, 16 centros de saúde (unidades básicas), 23 clínicas ou centros de especialidades, 91 consultórios e 1 pronto atendimento, Ituiutaba (MG) apresentou um total de 486 internações no mês de junho de 2014 e, dentre essas, 446 foram realizadas no Hospital São José (CNES, 2014).

Do total de 186 funcionários, 46 são médicos que atendem os níveis de atenção ambulatorial e hospitalar. Dos procedimentos realizados em 2014, 317 foram de caráter clínico e 129 cirúrgicos.

No Hospital São José, todos os tipos de atendimento (ambulatorial, internação, SADT - Serviço Auxiliar Diagnóstico e Terapia - e urgência) apresentam convênio no SUS e particular (CNES, 2014). No local são atendidas desde consultas até cirurgias de mama, do aparelho circulatório, dentre outras, com um total de 89 leitos distribuídos entre particular e sistema público.

Já o Hospital São Joaquim possui 30 leitos com instalações físicas de urgência e emergência, assim como de hospitalar e ambulatorial. Alguns de seus equipamentos

\footnotetext{
${ }^{7}$ Aparelho que realiza exames de pacientes identificados com alguma alteração relacionada ao câncer de mama, que objetiva analisar as lesões constatadas.

${ }^{8}$ As Unidades de Terapia Intensiva são locais diferenciados nos locais de saúde, que apresentam aparato tecnológico de média a alta complexidade, assim como uma constante avaliação médica do paciente que necessita de um acompanhamento específico.
} 
são: raio $\mathrm{X}$, ultrassom convencional, berço aquecido, bomba de infusão, desfibrilador, incubadora, endoscópio digestivo, dentre outros.

O Hospital Nossa Senhora D' Abadia possui sistema ambulatorial de internação nas duas esferas de convênio, pública e particular, sendo que as demais SADT e urgência - são apenas privadas. Com 34 leitos distribuídos entre clínica geral, cirurgia geral, cardiologia, pneumologia, neurologia, entre outros, o hospital conta com um quadro de serviços de saúde prestados, com destaque ao número de 24 cirurgias do aparelho digestivo, órgãos anexos e aparelho abdominal.

Assim, voltando às demais características da cidade, Ituiutaba (MG) possuía, em 2010, 1.585 estabelecimentos agropecuários, como Esteio Rural, Rural Pec, Agro campo. Recentemente, em 2014, ocorreu a inauguração do Shopping Rural da COOPERCITRUS.

De 2006 para 2012, 137 novas unidades de empresas surgiram em Ituiutaba (MG), atingindo um gasto total de salários de R\$339.607. Segundo o IBGE, o número de pessoas ocupadas também ascendeu, aumentando em 4.615 pessoas de 2006 a 2012 , chegando a um total, nesse último ano, de 23.376 pessoas.

No que tange ao segmento de comércio e serviços, existem supermercados de referência local, por exemplo, o Pontual, Supra e Ferreira. Ituiutaba (MG) vem se expandindo nesse segmento com a chegada da rede Bretas e, já em fevereiro de 2014, do hipermercado atacadista Mart Minas.

Nesse contexto, vale destacar a presença das lojas de departamentos, como Magazine Luiza, Eletrosom, Eletrozema, Ricardo Eletro, Lojas Americanas e Lojas Pernambucanas, que atendem a cidade e a região.

Sendo assim, é fundamental também entender a disponibilização das franquias na cidade de Ituiutaba (MG), visando analisar o seu processo de centralização e importância em sua rede urbana. As unidades são pouco diversificadas quando se observa o contexto do Triângulo Mineiro (MG), considerando a imponência de Uberlândia (MG).

Não obstante, Ituiutaba (MG) apresenta uma diversidade de franquias que vai desde o setor alimentício até as escolas de idiomas e de informática, conforme mostra o quadro 2.

A franquia da Morana, nomeada como Ituiutaba Morana, é umas das novas lojas nesse ramo na cidade que também se localiza na área central. Com mais de 200 unidades no país, atualmente a franquia também possui lojas no exterior, como nos Estados Unidos e em Portugal. Pertencente ao grupo Ornautus, a Morana é uma rede de acessórios femininos na qual, para ser um franqueado, é necessário um investimento de R\$ 270.000 a R\$ 380.000. Dessa forma, ela é uma loja que atende um público relativamente diferenciado devido aos valores de suas bijuterias. 
Quadro 2 - Ituiutaba (MG): franquias

\begin{tabular}{|l|c|}
\hline Alimentação & Cacau Show | Chiquinho Sorvetes | Chocolates Brasil Cacau \\
\hline Cosmético e perfumaria & O Boticário | Provanza Aromas e Sabores | L'acqua di Fiori | Água de \\
Cheiro
\end{tabular}

Fonte: Trabalho de Campo

Organização: Letícia Parreira Oliveira, 2014.

Nesse contexto, apenas uma instituição de ensino superior se encontra na área central, a UNOPAR ${ }^{9}$. Essa é uma unidade privada de ensino a distância - EAD - que se utiliza de meios tecnológicos de comunicação em que os alunos e professores realizam atividades educativas de forma diversificada, sem necessariamente ter a presença do docente no mesmo local em que o discente. As aulas têm dinâmicas e frequência diferenciadas, porém reconhecidas pelo MEC.

A FTM - Faculdade do Triângulo Mineiro -, localizada no bairro universitário, possui 3 cursos de graduação: administração, ciências contábeis e publicidade e propaganda, sendo apenas o último semestral. Além disso, apresenta 3 cursos de pós-graduação lato sensu, que são: MBA em gestão estratégica em finanças empresarial, MBA em gestão estratégia de pessoas e marketing, MBA em gestão estratégica em varejo.

O IFTM, a UEMG e a UFU são as três instituições públicas com ensino superior em Ituiutaba (MG). A primeira - Instituito Federal de Educação, Ciência e Tecnologia do Triângulo Mineiro - o IFTM, além de apresentar ensino médio e técnico, possui 2 cursos superiores e 4 cursos de pós-graduação latu sensu.

Outra instituição, a UEMG - Universidade Estadual de Minas Gerais -, foi instituída em 1963, ano em que começou suas atividades como a Fundação

\footnotetext{
${ }^{9}$ Universidade Norte do Paraná.
} 
Educacional de Ituiutaba (FEIT). "O terreno para sua instalação foi cedido pelo prefeito Samir Tannús [...] e o primeiro vestibular foi realizado em março de 1970 para os cursos de Ciências Biológicas, Matemática, Letras, Pedagogia e História” (OLIVEIRA, 2003, p. 170). Contudo, nessa época a Universidade ainda era privada, na qual os alunos pagavam mensalidades. Essa realidade foi modificada após 34 anos de sua fundação. Em abril de 2014, a Fundação Educacional de Ituiutaba (FEIT) se estadualizou com $10^{10}$ cursos superiores abertos para o vestibular de 2015. No segundo semestre de 2014, a instituição contava com 1.418 alunos matriculados, segundo dados da própria instituição.

De fato, o ensino superior sempre foi um ponto de atração de fluxos para Ituiutaba (MG), sobretudo, quando se trata de sua microrregião. Oliveira (2003, p. 176) já afirmava que, desde 2003, esse "tem sido um fator de polarização de Ituiutaba (MG) com outros centros, inclusive com alguns distantes, localizados nos estados do Maranhão, Mato Grosso do Sul, Pernambuco, Paraná”.

Já a UFU inaugurou em Ituiutaba (MG) seu campus, Faculdade de Ciências Integradas do Pontal (FACIP), no ano de 2007 com 9 cursos ${ }^{11}$. No ano de 2010 foram implantados mais 2: Engenharia de Produção e Serviço Social. Durante cinco anos, as aulas e atividades da instiuição foram realizadas nos prédios e espaço da UEMG. Atualmente, as atividades já são realizadas no espaço próprio da instituição.

Com 11 cursos, a instituição pública conta também com uma pós-graduação lato sensu (MBA em Gestão e Finanças Empresariais) e duas em stricto sensu (Ensino de Ciências e Matemática e em Geografia). Desse modo, a FACIP impactou na dinâmica dos fluxos regionais e intraurbanos de forma distinta da já realizada pelas demais unidades de ensino superior em Ituiutaba (MG). Portanto, um público diferenciado foi atingido por essas novas instalações.

Com 57 técnicos, 165 docentes e 2.093 alunos matriculados no primeiro semestre de 2014, pode-se constatar a existência de alunos de vários estados estudando na FACIP, com destaque para o número dos que vêm de São Paulo, do Triângulo Mineiro (MG), como um todo, e da microrregião de Ituiutaba (MG).

Dessa forma, "essas instituições têm promovido mudanças de ordem cultural, econômicas e espacial em Ituiutaba e potencializado a capacidade desta de atrair estudantes da região" (NASCIMENTO, MELO, 2011, p. 414).

\section{Considerações finais}

No caso específico desse trabalho, analisar os municípios de Frutal (MG) e Ituiutaba (MG) remete também a uma maior compreensão e entendimento sobre o

\footnotetext{
${ }^{10}$ Os cursos são: Agronomia, Psicologia, Direito, Engenharia da Computação, Engenharia Elétrica, Sistema de Informação, Pedagogia, Educação Física, Ciências Biológicas, Tecnologia em Produção Sucroalcooleira.

11 História, Geografia, Matemática, Física, Pedagogia, Química, Ciências Biológicas, Administração, Ciências Contábeis.
} 
Pontal do Triângulo Mineiro, o qual, devido a sua localização e acessibilidade rodoviária, apresenta relações com os estados de São Paulo, Mato Grosso e Goiás.

Toda essa contextualização da localização de Frutal (MG) e Ituiutaba (MG) é fundamental e também interfere na logística agropecuária, de forma que a produção se destina às indústrias e às beneficiadoras de grãos, sendo que algumas também se apresentam fora dos seus municípios. No caso de Frutal (MG), esse fator continua ligado à região paulista e, em Ituiutaba (MG), essa dinâmica se vincula de forma particular aos municípios no seu entorno.

Esses aspectos mostram a posição de importância de Frutal (MG) e Ituiutaba (MG) em detrimento de suas microrregiões. Frutal (MG) divide seu papel de centralidade com Iturama (MG), município este que ascende populacionalmente e apresenta atividades econômicas agroindustriais que dinamizam igualmente sua cidade. Esse fator pode ser justificado devido à extensão territorial da microrregião, bem como dos seus municípios que se apresentam em uma estrutura horizontal, distribuídos de forma que a porção oeste, regida por Iturama (MG), liga-se de forma mais direta e intensa a São Paulo, e a porção leste, polarizada por Frutal (MG), liga-se a Uberaba (MG) e Uberlândia (MG).

Já Ituiutaba (MG) tem papel determinante na centralidade, atraindo os fluxos de todas as cidades da sua microrregião. Tanto as atividades comerciais como as de saúde e de ensino superior são direcionadas a ela, o que torna possível constatar, junto a toda discussão do trabalho, que Ituiutaba (MG) tem uma importância maior para sua microrregião do que a que Frutal (MG) apresenta para a sua, lembrando que é importante avaliar a extensão territorial dos municípios, assim como das microrregiões. Ituiutaba (MG) apresenta uma ligação maior dos municípios pelas malhas rodoviárias, que convergem os fluxos das demais cidades a ela, sede da microrregião. Já Frutal (MG) possui uma microrregião com território extenso, com ligações espacializadas de forma horizontal, o que acaba por dividir os fluxos devido ao sentido das principais rodovias.

Além disso, as economias dos dois municípios pesquisados são regidas pelas atividades de serviços prestados. Contudo, Frutal (MG) apresenta uma dinâmica vinculada às atividades agropecuárias, com um campo que determina as movimentações e configurações do espaço urbano. Ituiutaba (MG) possui uma economia baseada no setor terciário e associada às atividades agroindustriais, sendo o setor industrial o segundo em arrecadação no PIB municipal (IBGE, 2011).

Portanto, as duas cidades possuem comércio e serviços voltados a atender a dinâmica do campo. Com a chegada das instituições de ensino e ampliação das já instaladas, o fluxo de pessoas se torna mais intenso, o que faz com que o setor terciário se amplie, visando satisfazer a essa nova demanda. Nesse contexto é que as franquias chegam às cidades, com foco em atingir públicos cada vez mais diferenciados, se 
tornando mais um elemento atrativo ao consumo, em vários sentidos, o que faz surgir outras atividades econômicas, que complementam a dinâmica comercial local.

O poder de centralização é destacado ao avaliar as dinâmicas exercidas pelo setor da saúde e as vinculadas ao ensino superior. A especialização e ampliação desses setores ampliam a ligação de Frutal (MG) e Ituiutaba (MG) com sua hinterlândia.

Dessa forma, a apresentação dos dados desse trabalho mostra as similaridades e as distinções entre os municípios e o trajeto percorrido durante os anos por cada um deles até os aspectos atuais, que os tornam cidades sedes das microrregiões geográficas e que geram centralidade.

Todos os questionamentos fomentarão novas ideias e outros problemas a serem pesquisados e compreendidos, uma vez que o processo de urbanização do Pontal do Triângulo Mineiro e a relação campo-cidade estabelecida nos seus municípios permite que muitos estudos sejam realizados, visando melhor entendê-lo.

\section{Referências}

ABF - Associação Brasileira de Franchising. Evolução do Setor 2003-2013.

Disponível em: < http://www.portaldofranchising.com.br/numeros-dofranchising/evolucao-do-setor-de-franchising> Acesso em: 05 set. 2014.

CNES - Cadastro Nacional de Estabelecimentos em Saúde. Disponível em:< http://cnes.datasus.gov.br/ >. Acesso em: 03 set. 2014.

HESPANHOL, Rosangela Aparecida Medeiros. Campo e cidade, rural e urbano no Brasil contemporâneo. Mercator (Fortaleza. Online), v. 12, p. 103-112-112, 2013.

IBGE - Cidades. PIB - Produto Interno Bruto de 2011. Rio de Janeiro: IBGE, 2011.

IBGE - Instituto Brasileiro de Geografia e Estatística. Assistência Médica Sanitária, 2009. Rio de Janeiro: IBGE: 2009.

IBGE - Instituto Brasileiro de Geografia e Estatística. Censo Agropecuário 2006. Rio de Janeiro: IBGE, 2006.

IBGE - Instituto Brasileiro de Geografia e Estatística. Censo Demográfico de 1950, Rio de Janeiro: IBGE, 1950.

IBGE - Instituto Brasileiro de Geografia e Estatística. Censo Demográfico de 1960, Rio de Janeiro: IBGE, 1960.

IBGE - Instituto Brasileiro de Geografia e Estatística. Censo Demográfico de 1970, Rio de Janeiro: IBGE, 1970.

IBGE - Instituto Brasileiro de Geografia e Estatística. Censo Demográfico de 1980, Rio de Janeiro: IBGE, 1980.

IBGE - Instituto Brasileiro de Geografia e Estatística. Censo Demográfico de 1990, Rio de Janeiro: IBGE, 1990. 
IBGE - Instituto Brasileiro de Geografia e Estatística. Censo Demográfico de 2000, Rio de Janeiro: IBGE, 2000.

IBGE - Instituto Brasileiro de Geografia e Estatística. Censo Demográfico de 2010, Rio de Janeiro: IBGE, 2010.

IBGE - Instituto Brasileiro de Geografia e Estatística. Estimativas Populacionais de 2014. Rio de Janeiro: IBGE, 2014.

IBGE - Instituto Brasileiro de Geografia e Estatística. Pesquisa Pecuária de 2000 e 2010. Rio de Janeiro: IBGE, 2000 b.

IBGE - Instituto Brasileiro de Geografia e Estatística. Pesquisa Pecuária de 2010. Rio de Janeiro: IBGE, 2010b.

IBGE - Instituto Brasileiro de Geografia e Estatística. Produção Agrícola Municipal de 2000. Rio de Janeiro: IBGE, 2000c.

IBGE - Instituto Brasileiro de Geografia e Estatística. Produção Agrícola Municipal de 2010. Rio de Janeiro: IBGE, 2010c.

IBGE - Instituto Brasileiro de Geografia e Estatística. Produção Agrícola Municipal de 2012. Rio de Janeiro: IBGE, 2012.

IPEADATA. Dados estatísticos. 2014. Disponível em: www.ipeadata.com.br . Acesso em 10 dez. 2014.

FONSECA, R. G.; SANTOS, J. C. dos. . A relação cidade-campo no município de

Ituiutaba (MG). Horizonte Científico (Uberlândia), v. 5, p. 1-29, 2011

LEFEBVRE, Henri. A revolução urbana. $3^{\mathrm{a}}$ reimp. Belo Horizonte: Editora da UFMG, 2008, 176p

NASCIMENTO, Plínio Andrade Guimarães do; MELO, Nágela Aparecida de. Ituiutaba (MG): reflexões sobre sua atuação na rede urbana regional a partir dos serviços de saúde e educação. Geo UERJ, Rio de Janeiro, ano 13, nº. 22, v. 02, p. 395421, jul./dez. 2011.

OLIVEIRA, Bianca Simoneli de. Ituiutaba (MG) na rede urbana tijucana:

(re)configurações sócio-espaciais no período de 1950 a 2000. 2003. 204f. Dissertação

(Mestrado em Geografia) - Instituto de Geografia, Universidade Federal de

Uberlândia, Uberlândia, 2003.

OLIVEIRA, Hélio Carlos Miranda de. Urbanização e cidades: análises da microrregião de Ituiutaba (MG). 2013. 431f. Tese (Doutorado em Geografia) Universidade Federal de Uberlândia

REIS DE PAULA, Adriano Silva. As transformações socioespaicias de Frutal MG. 162f. Dissertação (Mestrado em Geografia) Instituto de Geografia, Universidade Federal de Uberlândia, Uberlândia, 2012.

SANTOS, Joelma Cristina dos. A territorialização da agroindústria canavieira no Triângulo Mineiro e os (re)arranjos espaciais na Microrregião Geográfica de Ituiutaba 
(MG). In: Portugues, Anderson Pereira; Moura, Gerusa Gonçalves; Costa, Rildo Aparecido. (Org.). Geografia do Brasil Central: enfoques teóricos e particularidades regionais. 1ed.Uberlândia: Assis Editora, 2011, v. 1, p. 265-282

SANTOS, Milton. Metamorfoses do espaço habitado, fundamentos teórico e metodológico da geografia. $6^{\text {a }}$ edição. Hucitec. São Paulo 1988.

SANTOS, Joelma Cristina dos. Dos canaviais à "etanolatria": o (re)ordenamento territorial do capital e do trabalho no setor sucroalcooleiro na Microrregião Geográfica de Presidente Prudente-SP. 2009. 374f. Tese (Doutorado em Geografia) IG UFU, 2009, Uberlândia, 2009.

SPOSITO, M. Encarnação Beltrão. Estruturação urbana e centralidade. In: Encuentro De Geógrafos De América Latina, 3, 1991. Anais. Toluca/México. v. 1. p. 44-55.

UNICA - União da Indústria de cana-de-açúcar. Colheita safra 2013/2014. Disponível em: $<$ www.unicadata.com.br/historico-de-producao-e-

moagem.php?idMn=32\&tipoHistorico=4 >. Acesso em: 28 ago. 2014.

\footnotetext{
Letícia Parreira Oliveira

Possui graduação em Geografia pela Universidade Federal de Uberlândia, Faculdade de Ciências Integradas do Pontal (FACIP/UFU) (2012) e mestrado em Geografia pela Universidade Federal de Uberlândia (2015). Atualmente é doutoranda em Geografia (UFU) e bolsista da Fundação de Amparo à Pesquisa de Minas Gerais (FAPEMIG).

Av. João Naves de Ávila, 2121 - Bairro Santa Mônica - Uberlândia/ MG - CEP 38400-902

- E-mail: leticia.p.geo@gmail.com
}

\section{Vitor Ribeiro Filho}

Possui graduação em Geografia pela Universidade Federal de Uberlândia (1990), mestrado em Geografia pela Universidade Federal do Rio de Janeiro (1997) e doutorado em Geografia pela Universidade Federal do Rio de Janeiro (2004). Atualmente é professor do Instituto e do Programa de Pós-Graduação em Geografia da Universidade Federal de Uberlândia.

Av. João Naves de Ávila, 2121 - Bairro Santa Mônica - Uberlândia/ MG - CEP 38400-902

- E-mail: ribeirofilho.vitor@gmail.com

Recebido para publicação em dezembro de 2015

Aprovado para publicação em junho de 2016 